\title{
EXPERIÊNCIAS NA DOCÊNCIA: DESAFIOS E CONQUISTAS
}

\author{
Teaching Experiences: Challenges and Achievements \\ Experiencias de enseñanza: desafíos y logros
}

Aparecida de Jesus Soares Pereira ${ }^{* 1}$, Waldir Pereira da Silva ${ }^{1}$, Mirian Ferreira da Cunha ${ }^{1}$, Lidiana Alves dos Santos Sá ${ }^{1}$, Elizete Francisco de Portugal ${ }^{1}$

${ }^{1}$ Laboratório de Educação Musical, Curso de Licenciatura em Educação do Campo, Universidade Federal do

Tocantins-UFT, Arraias-TO, Brasil.

*Correspondência: Curso de Licenciatura em Educação do Campo, Universidade Federal do Tocantins - UFT, Campus Professor Dr. Sérgio Jacintho Leonor, Av. Juraíldes de Sena e Abreu, Setor Buritizinho/ sala 10 - Bloco Bala, Arraias - Tocantins, Brasil.CEP:77.330-000.e-mails: cida.soares@uft.edu.br

Artigo recebido em 03/04/2020 aprovado em 09/04/2020 publicado em 17/04/2020.

\section{INTRODUÇÃO}

Este relato de experiência descreve a participação de acadêmicos do Curso de Licenciatura em Educação do Campo - Códigos e Linguagens: Artes Visuais e Música no Programa Residência Pedagógica (RP). Tem-se como objetivo expor os benefícios adquiridos com o RP. O referido programa não contribui apenas com a formação discente, mas também proporciona novas vivências aos membros da escola campo, de modo especial, às preceptoras e aos alunos.

Segundo a Coordenação de Aperfeiçoamento de Pessoal de Nível Superior (CAPES), o Programa de Residência Pedagógica é uma das ações que integra a Política Nacional de Formação de Professores e tem por objetivo induzir o aperfeiçoamento da formação prática nos cursos de licenciatura, promovendo a imersão do licenciando na escola de educação básica.

Sendo assim, é possível observar que o Programa Residência Pedagógica (PRP), por ser disponibilizado somente a partir da segunda metade do curso, objetiva-se a aperfeiçoar a prática docente, pois é na segunda metade de um curso de licenciatura que ocorrem os estágios supervisionados. Por isso, a educação musical (...) é uma colagem de crenças e práticas. Seu papel na formação e manutenção dos [mundos musicais] - cada qual com seus valores, normas, crenças e expectativas - implica formas diferentes nas quais ensino e aprendizagem são realizados. Compreender esta variedade sugere que pode haver inúmeras maneiras nas quais a educação pode ser conduzida com integridade. A busca por uma única teoria e prática de instrução musical aceita universalmente, pode levar a uma compreensão limitada (ARROYO, 2002, p.20, APUD JORGENSEN, 1997, p.66).

Percebe-se o papel da educação musical na construção do conhecimento sociocultural, e por isso o estudo da música sugere um processo contínuo. Pensando neste processo, o RP do Curso de Educação do Campo busca incentivar a formação discente, ampliando o campo da vivência profissional e articulando teoria e prática profissional docente nas escolas campesinas.

\section{METODOLOGIAS E MATERIAIS}

Esse relato surge a partir de uma experiência na área da docência na educação básica, contemplando as diversas etapas do processo enquanto residentes no Programa Residência Pedagógica, que é uma atividade 
de formação da docência desenvolvida em escolas públicas da educação básica.

Uma destas atividades foram realizadas na Escola campo "Colégio Estadual Professora Irany Nunes do Prado", zona rural do município de Monte Alegre de Goiás, uma pequena comunidade com cerca de 1.200 habitantes, tendo como vizinhos pequenas propriedades de agricultores. De acordo com o relato dos moradores antigos do lugar, no princípio se chamava "Escola Reunidor Municipal Prata", que levava o nome da comunidade; a escola funcionava na área da casa da própria professora, a Sra. Eugênia Amado. Com o passar do tempo e crescimento da comunidade se fez necessário uma escola maior que atendesse a demanda da região. Foi então que um fazendeiro da região doou 5 (cinco) alqueires de sua fazenda para a construção de um prédio escolar. Após a construção da escola, a população começou a se mudar para proximidades para que os filhos pudessem estudar, criando assim um novo distrito, o Distrito do Prata. No fim da década de 70 a escola que atendia a primeira fase passou a funcionar o Ensino Fundamental, e em 1998 recebeu o nome de Professora Irany Nunes do Prado. Em 2003 passa a funcionar o Ensino Médio.

De lá pra cá não mudou muita coisa por falta de incentivo governamental. O quadro de funcionários é pequeno para atender a demanda da escola, sendo a maioria de contrato temporário. As atividades pedagógicas são realizadas de forma precária por falta de recursos financeiros, infraestrutura física e pedagógica. A escola desenvolve os projetos definidos pela SEDUC-GO, e ações contidas no Plano de Desenvolvimento da Escola - PDE que assim diz:

Uma educação básica de qualidade. Essa é a prioridade do Plano de Desenvolvimento da Educação (PDE). Investir na educação básica significa investir na educação profissional e na educação superior porque elas estão ligadas, direta ou indiretamente. Significa também envolver todos - pais, alunos, professores e

DOI: http://dx.doi.org/10.20873/uftsupl2020-8813 gestores, em iniciativas que busquem o sucesso e a permanência do aluno na escola. (PDE, 2008)

Percebe-se que a prioridade do PDE é uma educação básica de qualidade. Mas pergunta-se: Como? De acordo com informações contidas no Projeto Político Pedagógico - PPP e em conversa com o corpo docente da escola observam-se os desafios e dificuldades enfrentados, como falta de participação da família no processo educacional, o que acarreta deficiências na aprendizagem dos alunos e evasão escolar pela falta de professores com formação nas áreas específicas. Falta também assistente social, psicólogo para ter uma melhoria no ensino e na aprendizagem.

Conforme o Art. 205 da Constituição Federal de 1988, a educação é direito de todos e dever do Estado, e inclusive da família (BRASIL, 1988). O acompanhamento na escola dos alunos pelos pais ou responsáveis legais deveria ser uma responsabilidade cobrada rigorosamente pela instituição de ensino e pelo Estado.

Ao fazer a análise da escola nota-se que a mesma não possui instrumentos musicais ou materiais para o conteúdo de Artes. Muitas vezes percebe-se que as aulas de Artes e os professores desta disciplina apresentam-se como recursos integrantes em comemorações e eventos. O Art. 210 da Constituição Federal de 1988 diz:

Serão fixados conteúdos mínimos para o Ensino Fundamental, de maneira a assegurar formação básica comum e respeito aos valores culturais e artísticos nacionais e regionais. (CONSTITUIÇÃO FEDERAL, 1988, p. 139).

As funções e contribuições que as Artes desenvolvem na sociedade não podem ser ignoradas. Elas possibilitam o autoconhecimento da expressão e criação. $\mathrm{O}$ ensino de Artes possibilita conhecer mais o nosso povo e nossa história, suas ideias e suas concepções de mundo.

Revista Desafios - v. 7, n. Supl. RP-UFT, 2020 


\section{RESULTADOS E DISCUSSÃO}

Desta forma, o PRP se faz importante na vida acadêmica, e também para as escolas campo. Os trabalhos são realizados visando contribuir da melhor forma possível para o ensino nas escolas.

Como a escola se localiza na zona rural, cabe aos residentes adequar os projetos e ações a serem desenvolvidos de acordo com a realidade e as limitações da unidade e comunidade escolar. Sendo assim, os trabalhos artísticos foram voltados à cultura local, objetivando fortalecer o vínculo entre a escola e a comunidade. É fundamental o auxílio das preceptoras das escolas, pois além de transmitirem confiança aos residentes, elas adquirirem novas experiências que podem contribuir com suas práticas pedagógicas e nas relações entre preceptor-residente e residente-aluno. Não está em pauta a transmissão, e sim a construção de novos conhecimentos. É gratificante perceber que os trabalhos desenvolvidos na escola campo contribuíram de forma positiva para os participantes.

\section{CONCLUSÃO}

Foi possível observar que no decorrer das atividades os alunos foram tendo uma concepção diferente sobre Arte e Música na escola, pois as escolas públicas do Estado do Tocantins têm essa carência de profissionais formados nas áreas específicas.

Embora muitas dificuldades tenham acontecido no decorrer desse projeto, um dos maiores problemas foi o deslocamento de um percurso de 218 $\mathrm{km}$, a percorrer até a escola campo, que fica no Estado de Goiás. A motivação a continuar o projeto é o desejo latente em aperfeiçoar no ser professor e adquirir experiência na prática da docência.

Ao fim do trabalho pode-se concluir que o projeto foi bem desenvolvido. Também foi possível compreender que o programa foi necessário para o aperfeiçoamento na área docente. Enfim são diversos os benefícios que a RP oferece aos acadêmicos de Licenciatura e aos membros das escolas campo.

\section{AGRADECIMENTOS}

Agradeço a Deus, pelo favor imerecido, ao Curso de Licenciatura em Educação do Campo da UFT, por tornar possível a realização do Programa RP, à CAPES pelo apoio financeiro, a Secretaria de Educação com as Escolas-Campo pela parceria, e a todos que contribuíram direta e indiretamente nos incentivando a prosseguir nos momentos em que surgiram pensamentos em desistir.

Todos os autores declararam não haver qualquer potencial conflito de interesses referente a este artigo.

\section{REFERÊNCIAS}

ARROYO, M. Educação musical na contemporaneidade. ANAIS do II Seminário Nacional de Pesquisa em Música da UFG, 2002.

BRASIL. Constituição da República Federativa do Brasil de 1988. Disponível em http://www.planalto.gov.br/ccivil_03/constituicao/co nstituicao.htm. Acesso em 20 de novembro de 2019.

Brasil. Plano de Desenvolvimento da Educação. 2008. Disponível em http://portal.mec.gov.br/arquivos/Bk_pde/oquee.html. Acesso em 20 de novembro de 2019.

CAPES. Programa de Residência Pedagógica. 2018. Disponível em: https://capes.gov.br/educacaobasica/programa-residencia-pedagogica. Acesso em 20 de novembro de 2019. 